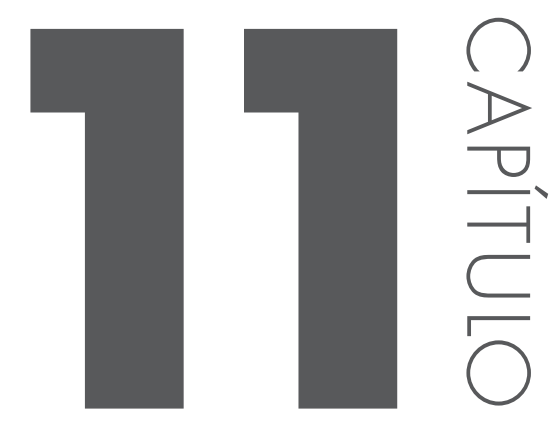

\title{
IDENTIFICAC̣ÃO dOS METABOLITOS DA OXIDAção aNódica do dIClofenaC POR HPLC
}

Barbosa, Andreia Daniane 1,2;

Santos, Dália ${ }^{2}$;

Ciríaco, Lurdes ';

Pacheco, Maria José 2;

Lopes, Ana Carreira 2*

'Departamento de Química, Regional Catalão, Universidade Federal de Goiás, GO-Brasil

2 UMTP e Departamento de Química, Universidade da Beira Interior, 6201-001 Covilhã, Portugal

*email: analopes@ubi.pt 
Resumo: Esta pesquisa tem como objetivo principal estudar a eficiência de degradação eletroquímica do Diclofenac, utilizando como ânodos diamante dopado com boro (BDD) e Ti/Pt/SnO2-Sb, e identificar, por HPLC, os metabolitos resultantes da oxidação anódica. Os ensaios de eletrodegradação foram monitorizados por determinações da demanda química de oxigênio (DQO) e de carbono orgânico total (COT). Foram também realizados espectros de absorção no ultravioleta-visível e medições de $\mathrm{pH}$ e de condutividade. Os resultados obtidos mostram que os dois materiais de eletrodo são apropriados como ânodos para a degradação do Diclofenac, pois há uma redução da CQO, do TOC e da absorvência, a $276 \mathrm{~nm}$, ao longo do tempo. Os resultados de $\mathrm{pH}$ indicam-nos a formação de ácidos carboxílicos e da condutividade apontam para a possibilidade de formação de espécies poliméricas. Os melhores resultados em termos de remoção da carga orgânica foram obtidos com o ânodo de BDD com remoções de CQO de 70 e 38\%, de TOC de 77 e $42 \%$ e de absorvência de 86 e $31 \%$, respetivamente para os ânodos de $\mathrm{BDD}$ e de $\mathrm{Ti} / \mathrm{Pt} / \mathrm{SnO} 2-\mathrm{Sb}$. A identificação dos produtos resultantes da oxidação anódica fez-se por HPLC, tendo-se identificado os seguintes ácidos carboxílicos resultantes da degradação do Diclofenac: ácido oxálico, ácido maleico, ácido oxâmico, ácido fórmico e ácido acético. Assim, durante a primeira parte do ensaio a razão $\triangle \mathrm{TOC} /$ $\triangle C Q O$ observada corresponde à degradação do Diclofenac, enquanto a observada na segunda parte do ensaio corresponderá à degradação dos ácidos carboxílicos formados.

\section{Palavras-chave: Ti/Pt/SnO2-Sb; BDD; Oxidação Eletroquímica}




\section{Introduc̣ão}

A criação de novos medicamentos está em franco crescimento, podendo proporcionar aos humanos curas para novas doenças. Contudo, as mesmas moléculas que curam seguem contaminando e causando riscos para toda a população, tornandose uma ameaça ambiental (Costa e Costa, 2011). Os fármacos podem contaminar de forma direta ou indireta o meio ambiente, provocando efeitos negativos no equilíbrio do ecossistema ecológico e trazendo danos para a saúde humana (Bila e Dezotti, 2003). Assim, o tratamento de águas residuais tornou-se um processo importante para o controle da polvição. 
De entre os medicamentos já encontrados em águas residuais, destaca-se o diclofenac, um anti-inflamatório não esteróide. Ele é bastante consumido pela população, pois é um medicamento simples, que não exige uma prescrição médica, tornando-se assim um alvo fácil de uso indevido por automedicação (Kopin et al. 2002; Paterson et al. 2002).

Além dos processos biológicos normalmente usados no tratamento de efluentes, e que já provaram ser pouco eficientes na remoção de fármacos tecnologias físicas e químicas podem ser utilizadas como: filtração, adsorção, coagulação, floculação e flotação. Também a aplicação de processos oxidativos avançados (POAs) tem sido alvo de investigação nas últimas décadas. Estes processos são caracterizados pela formação in situ de radicais hidroxila, com um poder oxidativo muito forte. Incluído nesta categoria de processos, as técnicas eletroquímicas têm sido alvo de investigação, principalmente a oxidação anódica (Zhao et al. 2009).

A oxidação eletroquímica pode ocorrer por troca direta do elétron entre o composto orgânico e a superfície do elétrodo ou, de forma indireta, dando-se a oxidação dos polventes através de espécies eletroativas oxidantes formadas no ânodo, como o radical hidroxila formado a partir da eletrólise de água. A principal vantagem das tecnologias eletroquímicas é a sua compatibilidade ambiental, porque o reagente principal é o elétron. Assim, a degradação oxidativa pode tornar-se num processo eficiente para a eliminação dos polventes (Bertazzoli e Pelegrini, 2002).

A eliminação de polventes orgânicos por oxidação eletroquímica requer um ânodo com condutividade elétrica elevada e boa estabilidade mecânica e eletroquímica. Têm sido utilizados vários materiais de eletrodo, como o diamante dopado com boro (BDD - boron-doped Diamond), o $\mathrm{PbO}_{2}$ e o $\mathrm{SnO}_{2}$, que já mostraram um desempenho bom na degradação dos compostos farmacêuticos (Santos et al. 2013; Lima et al. 2013; Batista et al. 2011).

Embora os resultados de oxidação eletroquímica obtidos com a utilização do $\mathrm{PbO}_{2}$ e o $\mathrm{BDD}$ sejam especialmente notáveis, o BDD é mais reativo que o $\mathrm{PbO}_{2}$, levando uma eficiência superior na corrente e um menor consumo de energia específica (Zanin et al. 2013).

\section{Processos Oxidativos Avançados}

Os processos oxidativos avançados (POAs) são processos de tratamento de água e efluentes que ocorrem à pressão e temperatura ambientes e que envolvem a geração de radicais hidroxila em quantidades suficientes para promover a purificação da água (Glaze et al. 1987), apresentando uma enorme aplicabilidade em sistemas ambientais, funcionando como um tipo de tratamento químico que pode servir para a purificação de ar, desinfeção e a purificação de água e de efluentes industriais (Freire et al. 2000). 
Os POAs têm a capacidade de transformar a maioria dos contaminantes orgânicos em dióxido de carbono, água e íons inorgânicos, através de reações de degradação que envolvem espécies transitórias oxidantes como os radicais hidroxila, POAs são processos limpos e podem ser usados para destruir compostos orgânicos na fase aquosa ou gasosa ou na matriz sólida (Pera-Titus et al. 2004).

\subsection{Tratamento Eletroquímico}

A eletroquímica oferece várias opções para o meio ambiente, em particular para efluentes aquosos, sendo capaz de oxidar ou reduzir ions metálicos, cianetos, compostos organoclorados, hidrocarbonetos aromáticos e alifáticos, baseando-se na eletro-oxidação direta dos compostos, sendo que nesse processo o elétrons é o principal reagente, evitando o uso de outros compostos químicos que podem ser tóxicos (Freire et al. 2000).

Nos últimos anos, os processos eletroquímicos têm demonstrado a sua eficiência no tratamento de efluentes contendo polventes orgânicos refratários e tóxicos (Panizza e Cerisola, 2005; Martínez-Huitle e Brillas, 2009; Panizza e Cerisola, 2009). Nos processos eletroquímicos, a oxidação ocorre no ânodo, que pode ser de diferentes materiais, na presença de um eletrólito (Panizza e Cerisola, 2009).

A oxidação eletroquímica oferece diversas vantagens para a prevenção e solução dos problemas ambientais. Trata-se de um processo limpo que pode funcionar a baixas temperaturas e, na maioria dos casos, sem adição de qualquer reagente nem formação de lamas, utilizando equipamento simples e de fácil operação (Santos et al. 2008; Anglada et al. 2009; Brinzila et al. 2013).

Esta pesquisa tem como objetivo principal estudar a eficiência de degradação eletroquímica de compostos farmacêuticos, neste caso o diclofenac, utilizando como ânodos o $\mathrm{BDD}$ e $\circ \mathrm{Ti} / \mathrm{Pt} / \mathrm{SnO}_{2}$ - $\mathrm{Sb}$, sendo a eficiência da eletrodegradação monitorada por determinações da demanda química de oxigênio (DQO), de carbono orgânico total (COT) e por análise de espectros de absorção de ultravioleta-visível. A identificação dos metabolitos da oxidação anódica do Diclofenac será feita pela técnica de HPLC

\section{Material e Método}

As características dos reagentes utilizados estão apresentadas na (Tabela 1). Além dos reagentes citados a seguir, foram usados os equipamentos descritos na (Tabela 2).

- Solução Padrão de Dicromato de Potássio (0,0417 M);

- Solução de Ácido Sulfúrico / Sulfato de prata; 
- Solução de Digestão de Dicromato de Sódio;

- Solução de Sulfato Ferroso Amoniacal (SFA) 0,05 M;

- Indicador Ferroína;

- Solução Padrão de Hidrogenoftalato de Potássio (HPK);

- Solução de Ácido Sulfúrico 0, 04 mM (eluente para HPLC);

Nos ensaios de degradação eletroquímica usaram-se os elétrodos de BDD (marca CSEM) e o eletrodo de $\mathrm{Ti} / \mathrm{Pt} / \mathrm{SnO}_{2}-\mathrm{Sb}$ com área de $10 \mathrm{~cm}^{2}$, preparado como descrito em (Santos et al. 2014).

Tabela 1. Reagentes utilizados na preparação da amostra e HPLC.

\begin{tabular}{|l|l|l|l|l|l|}
\hline Reagentes & $\begin{array}{l}\text { Forma } \\
\text { Molecular }\end{array}$ & Pureza \% & Marca & CAS & Massa molecular \\
\hline Sulfato de sódio & $\mathrm{Na}_{2} \mathrm{SO}_{4}$ & $99 \%$ & $\begin{array}{l}\text { Carlo } \\
\text { Erba }\end{array}$ & $7757-82-6$ & $142,04 \mathrm{~g} \mathrm{~mol}^{-1}$ \\
\hline $\begin{array}{l}\text { Diclofenac de } \\
\text { sódio }\end{array}$ & $\mathrm{C}_{14} \mathrm{H}_{10} \mathrm{Cl}_{2} \mathrm{NNaO}_{2}$ & - & Sigma & $15307-79-6$ & $296,14 \mathrm{~g} \mathrm{~mol}^{-1}$ \\
\hline $\begin{array}{l}\text { Ácido Sulfúrico } \\
0,1 \mathrm{M}\end{array}$ & $\mathrm{H}_{2} \mathrm{SO}_{4}$ & $\begin{array}{l}\mathrm{HPLC} \\
\text { grade }\end{array}$ & Fluka & $7664-93-9$ & $98,079 \mathrm{~g} \mathrm{~mol}^{-1}$ \\
\hline
\end{tabular}

Tabela 2. Equipamentos utilizados com respetivas marcas e modelos.

\begin{tabular}{|c|c|c|c|}
\hline \multicolumn{2}{|c|}{ Equipamento } & Marca & Modelo \\
\hline \multirow{4}{*}{ 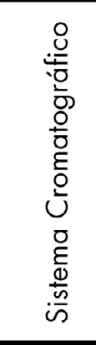 } & \begin{tabular}{|lr} 
Unidade & de \\
desgaseificação & dos \\
elventes & \\
\end{tabular} & \multirow{4}{*}{ Shimadzu } & $\begin{array}{l}\text { DGU-As } \\
\text { prominence }\end{array}$ \\
\hline & Bomba Quarternária & & LC-20 AD \\
\hline & Forno para coluna & & CTO-20Ac \\
\hline & $\begin{array}{l}\text { Detector } \\
\text { Espectrofotométrico de } \\
\text { fotodíodos }\end{array}$ & & SSPD-M2OA \\
\hline \multicolumn{2}{|c|}{$\begin{array}{l}\text { Digestor da Demanda Química de } \\
\text { Oxigênio (DQO) }\end{array}$} & Merck Spectoroquant & TR 420 \\
\hline \multicolumn{2}{|c|}{ Balança Analítica } & Mettler Toledo & MS 204S - 01 \\
\hline \multicolumn{2}{|c|}{ Carbono Orgânico Total (TOC) } & Shimadzu & TOC $-\mathrm{V}_{\mathrm{CSH}}$ \\
\hline \multicolumn{2}{|c|}{ Titulador automático } & Metrohm & 876 Dosimat plus \\
\hline \multicolumn{2}{|c|}{ Placa de agitação } & Agimatic & - \\
\hline \multicolumn{2}{|c|}{ Fonte de alimentação } & $\begin{array}{l}\text { GW- Laboratory de power } \\
\text { supply model }\end{array}$ & BPS - 3030D \\
\hline \multicolumn{2}{|l|}{ Vortéx } & VWR & VV3 \\
\hline \multicolumn{2}{|c|}{$\begin{array}{l}\text { Espectrofotómetro de absorção UV- } \\
\text { Vis }\end{array}$} & Shimadzu & UV - 1800 \\
\hline \multicolumn{2}{|c|}{ Medidor de condutividade } & Mettler Toledo & - \\
\hline \multicolumn{2}{|c|}{ Medidor de $\mathrm{pH}$} & Mettler Toledo & - \\
\hline
\end{tabular}




\subsection{Demanda Química de Oxigênio (DQO)}

A demanda química de oxigênio (DQO) é um parâmetro que mede a quantidade de oxigênio consumido por materiais e por substâncias orgânicas e minerais quando se oxidam em condições definidas. No caso de águas, o parâmetro torna-se particularmente importante por determinar o potencial polvidor de efluentes domésticos e industriais, assim como, por estimar o seu impacto sobre os ecossistemas aquáticos.

Assim, a demanda química de oxigênio é definida como a quantidade de oxidante específico que reage com a amostra em condições controladas. A quantidade de oxidante específico consumido é expresso em relação ao seu oxigênio equivalente. Devido às suas propriedades químicas únicas, o íon dicromato $\left(\mathrm{Cr}_{2} \mathrm{O}_{7}{ }^{2}\right)$ é o oxidante específico para o método de refluxo fechado, seguido de titulação, utilizado neste trabalho. Nos diferentes tipos de testes da DQO, existe uma redução do dicromato a ín crômio $\left(\mathrm{Cr}^{3+}\right)$. Numa amostra, tanto os componentes orgânicos como os inorgânicos são sujeitos à oxidação, mas na maioria, o componente orgânico predomina e tem mais interesse. Na prática faz-se uma titulação por refluxo em que se titula a quantidade de dicromato em excesso, determinando-se assim o oxidante consumido durante a reação, que será convertido em miligramas de oxigênio consumido por volume de amostra.

Para a determinação experimental da DQO realizam-se os seguintes itens:

- Em cada um dos tubos da DQO coloca-se $1 \mathrm{~mL}$ de dicromato, 1, $5 \mathrm{~mL}$ das amostras (ou água destilada, para fazer um branco, ou $1,5 \mathrm{~mL}$ de Solução Padrão de Hidrogenoftalato de Potássio, para fazer um padrão) e $2 \mathrm{~mL}$ da Solução de Ácido Sulfúrico/Sulfato de Prata.

- Levou-se todos os tubos ao digestor (Merck Spectoroquant) durante 2 horas à temperatura de $150^{\circ} \mathrm{C}$.

- Deixam-se arrefecer os tubos e faz-se uma titulação (titulador automático Metrohm, 876 Dosimat plus) com uma solução de Sulfato Ferroso Amoniacal (SFA) 0,05 $\mathrm{M}$ e o indicador ferroína, tendo o cuidado de anotar o valor de titulante gasto e do fator $\mathrm{f}$, previamente determinado para $\circ$ titulante a ser usado (Eaton et al. 1995). 


\subsection{Carbono Orgânico Total (COT)}

O Carbono Orgânico existente em águas, no geral, pode ser proveniente de vários compostos orgânicos, em vários estados de oxidação e, particularmente em águas de esgotos, é uma medida qualidade de água e de solo considerando o montante de carbono orgânico existente na amostra. A medição de carbono orgânico (TOC) em água envolve medir o carbono inorgânico inicial, $\mathrm{Cl}$, oxidar completamente todos os compostos orgânicos para a forma de $\mathrm{CO}_{2}$ e quantificar este $\mathrm{CO}_{2}(\mathrm{CT})$, por um detector de infra-vermelho, sendo depois o TOC dado pela diferença entre o $\mathrm{CT}$ e $\mathrm{Cl}$ (Teixeira e Jardim, 2004).

Nas determinações de TOC utilizou-se o equipamento TOC - Shimadzu bem como tubos próprios para o TOC, onde se colocou $3 \mathrm{~mL}$ da amostra e $12 \mathrm{~mL}$ de água destilada, tendo-se vedado os tubos com folha de alumínio e aguardado os resultados gerados no computador para as concentrações.

\subsection{Espectrofotometria Ultravioleta - Visível}

As amostras retiradas ao longo do tempo de eletrodegradação foram analisadas por espectrofotometria de absorção no UV-Vis, tendo sido traçados espectros no intervalo de comprimento de onda entre 200 e $800 \mathrm{~nm}$, usando o espectrofotômetro da Shimatzu. Para traçar os espectros de absorção no UV-Vis, as amostras, retiradas ao longo do tempo, foram diluídas 5 vezes. Para as determinações foram usadas células de quartzo com um percurso óptico de $1,00 \mathrm{~cm}$.

\subsection{Cromatografia Líquida de Alta Eficiência (HPLC)}

A cromatografia líquida de alta eficiência é mais usada dentre as técnicas analíticas, o método devem a sua elevada sensibilidade, fácil adaptação para determinações quantitativas precisas e à separação de espécies não voláteis ou termicamente instáveis, sua ampla sensibilidade tem um grande interesse para a indústria e para a pesquisa científica para pode realizar diversos tipos de análises.

A análise dos ácidos carboxílicos que se formam durante a eletrodegradação do diclofenac foi efetuada por cromatografia de exclusão iónica. Para esta análise foi usada uma coluna Aminex HPX - 87H da Bio-Rad, com dimensões $300 \mathrm{~mm} \times 7,8 \mathrm{~mm}$ (d.i.). Nesta análise foram usadas as seguintes condições cromatográfica: 
- Fase móvel: solução de ácido sulfúrico $4 \mathrm{mM}$, modo de eluição isocrático

- Fluxo: $0,6 \mathrm{~mL} / \mathrm{min}$

- Volume de injecção: $100 \mu \mathrm{L}$

- Temperatura da coluna: $35^{\circ} \mathrm{C}$

- Comprimento de onda de detecção: $210 \mathrm{~nm}$

Todas as amostras e os elventes foram previamente filtradas usando, respectivamente, filtros de seringa com uma membrana de polipropileno de 0,45 $\mu \mathrm{m}$ (VWR International), e filtros de polipropileno hidrofílico (Pall Life Sciences), de 0,45 um (filtração a vácuo). Todas as soluções aquosas foram preparadas usando água desionizada tipo Mili-Q.

\section{Resulfados e Discussão}

\subsection{Degradação eletroquímica do Diclofenac com os eletrodos de $\mathrm{BDD}$ e de $\mathrm{Ti} / \mathrm{Pt} / \mathrm{SnO}_{2}-\mathrm{Sb}$}

Neste capítulo será apresentado os resultados obtidos na degradação eletroquímica do diclofenac com os dois ânodos utilizados: $\circ \mathrm{Ti} / \mathrm{Pt} / \mathrm{SnO}_{2}-\mathrm{Sb}$ e o $\mathrm{BDD}$. $\mathrm{Na}$ figura 1, relativa aos resultados conseguidos com o eletrodo de $\mathrm{Ti} / \mathrm{Pt} / \mathrm{SnO}_{2}-\mathrm{Sb}$, podemos observar que houve degradação do diclofenac, pois há uma aparente redução da DQO, do COT e da absorvência ao longo do tempo. Há ainda a registar uma ligeira diminuição do $\mathrm{pH}$ ao fim das $6 \mathrm{~h}$ de ensaio, que deve estar relacionada com a formação de ácidos carboxílicos, bem documentada na literatura (Panizza e Cerisola, 2009). A condutividade também sofre uma ligeira redução ao longo do tempo, que poderá estar relacionada com formação de espécies poliméricas, pois observa-se a formação de turvação nas amostras recolhidas após algum tempo. Assim, se a condutividade não for medida de imediato, o que aconteceu, pode haver a formação dessas espécies e a consequente redução na condutividade.

Em relação aos resultados obtidos com o ânodo de BDD na figura 2, verifica-se uma remoção acentuada da carga orgânica ao fim das $6 \mathrm{~h}$ de ensaio, que se traduz por remoções elevadas de DQO, COT e absorvência. Em relação ao $\mathrm{pH}$, há uma diminuição inicial, seguida de um aumento. A primeira parte da curva deve estar associada à formação de ácidos carboxílicos, estando a parte de aumento do $\mathrm{pH}$ relacionado com a formação de um excesso de radicais hidroxila, que acontece quando a matéria orgânica em solução já é muito reduzida e a densidade de corrente 
elevada. Em relação à condutividade, o comportamento é semelhante, havendo uma parte inicial de decréscimo, relacionada com a formação de macromoléculas no tubo onde a amostra recolhida foi colocada, seguida de um aumento, quando as espécies em solução já não tendem a polimerizar.

Na figura 3 comparam-se os resultados obtidos com os dois ânodos. Verifica-se que a remoção da carga orgânica, medida como DQO e COT, e a remoção de absorvência, medida a $276 \mathrm{~nm}$, são mais rápidas com o ânodo de BDD. Na figura 3, alínea $c$, encontra-se traçada a variação do COT com a DQO, ao longo do tempo, para os ensaios realizados com os dois ânodos. Esta relação dá uma medida da mineralização ocorrida, pois quanto maior for a razão $\triangle C O T / \triangle D Q O$ maior é a mineralização (Pacheco et al. 2007). É muito interessante verificar que existem duas fases distintas, com diferentes declives, mas que os dois materiais apresentam comportamentos/declives semelhantes, apenas com uma desfagem no tempo.

Estas duas fases devem estar relacionadas com o facto de no início termos apenas diclofenac para ser degradado e, numa fase posterior, existirem outros metabolitos, que vão conduzir a eficiências de combustão diferentes (Pacheco et al. 2007). 

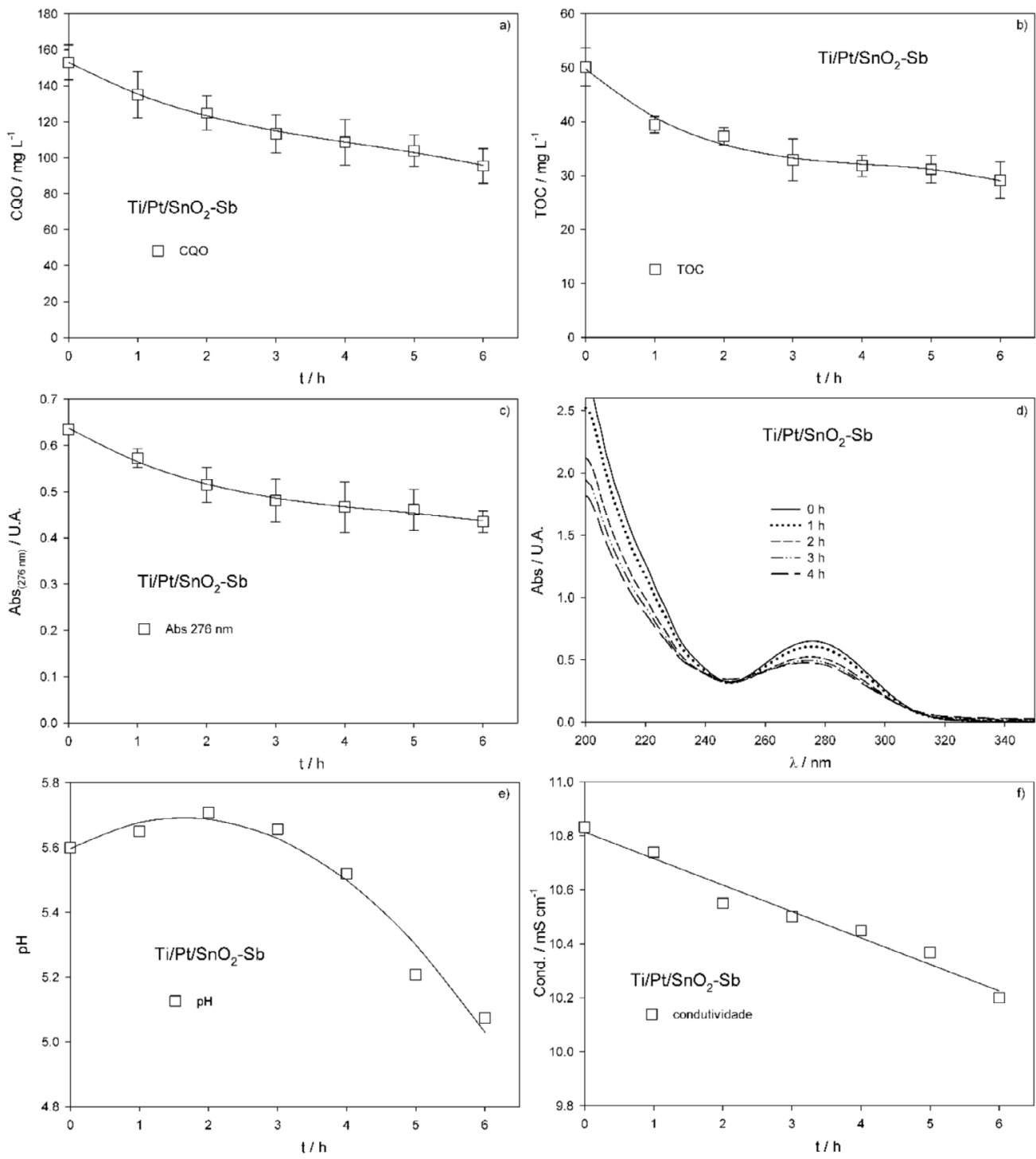

Figura 1. Evolução de a) DQO, b) COT, c) absorvência, medida a 276 nm, d) dos espectros de absorção, e) $\mathrm{pH}$ e f) condutividade ao longo do tempo de ensaio durante a oxidação eletroquímica realizada com o ânodo de Ti $/ \mathrm{Pt} / \mathrm{SnO}_{2}-\mathrm{Sb}$ a uma densidade de corrente de $30 \mathrm{~mA} / \mathrm{cm}^{2}$. 

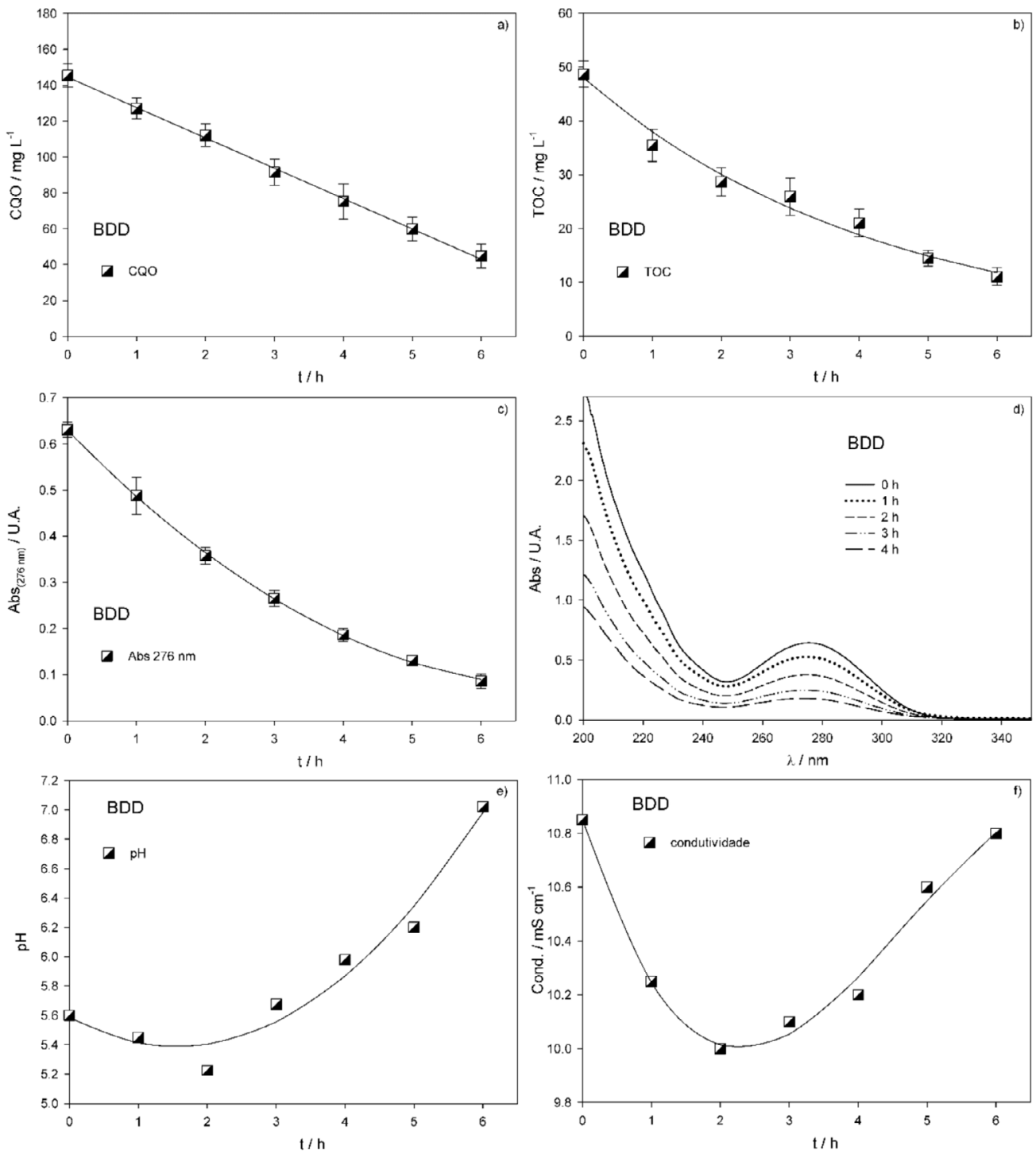

Figura 2. Evolução de a) DQO, b) COT, c) absorvência, medida a $276 \mathrm{~nm}$, d) dos espectros de absorção, e) $\mathrm{pH}$ e f) condutividade ao longo do tempo de ensaio durante a oxidação eletroquímica realizada com o ânodo de BDD a uma densidade de corrente de $30 \mathrm{~mA} / \mathrm{cm}^{2}$. 

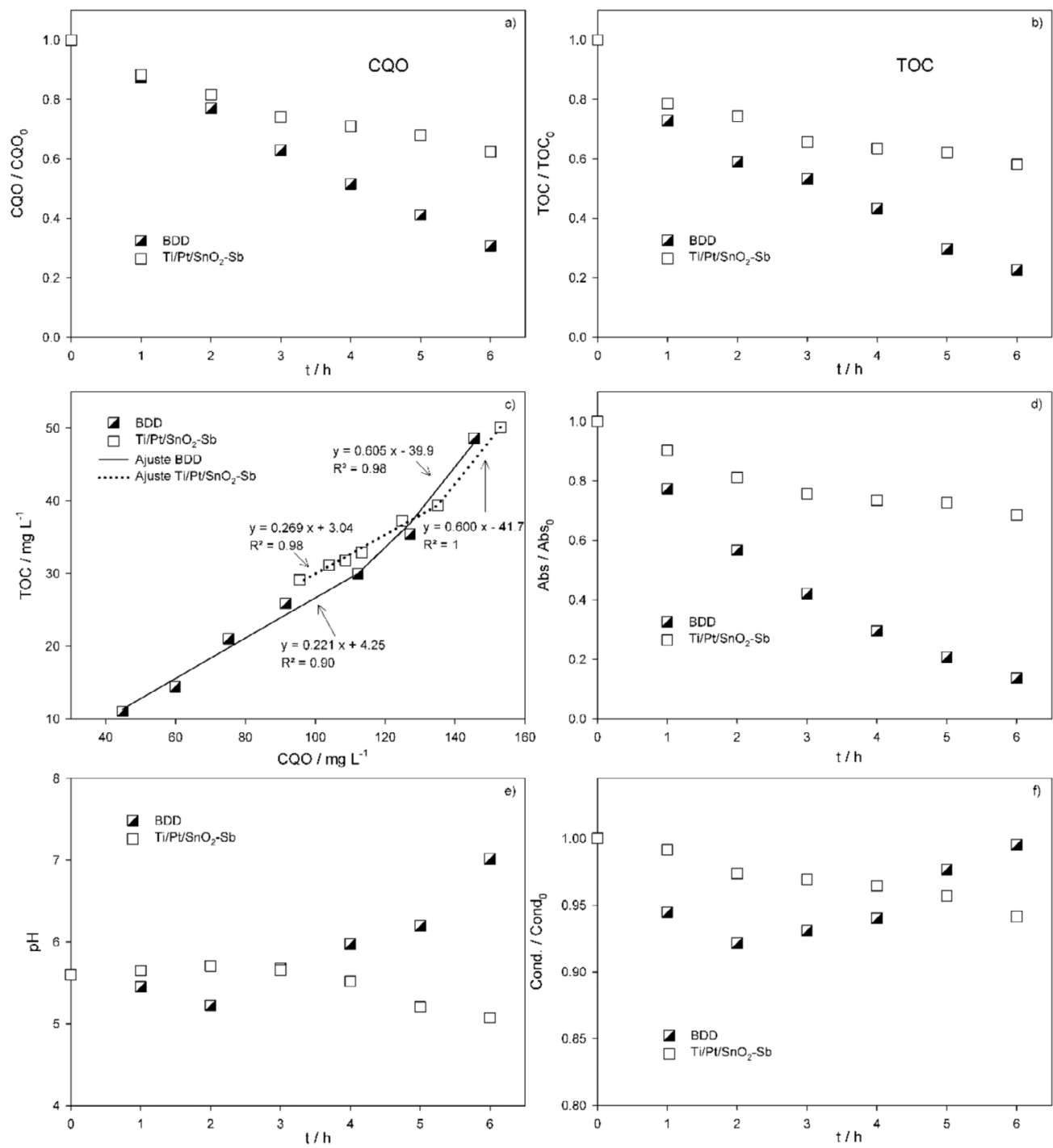

Figura 3. Comparação entre os resultados obtidos com os ânodos de $\mathrm{Ti} / \mathrm{Pt} / \mathrm{SnO}_{2}-\mathrm{Sb}$ e de $\mathrm{BDD}$ ao longo do tempo de ensaio durante a oxidação eletroquímica de soluções de $100 \mathrm{mg} / \mathrm{L}$ de diclofenac a uma densidade de corrente de $30 \mathrm{~mA} / \mathrm{cm}^{2}$. Valores relativos de a) DQO e b) COT; c) Relação COT vs DQO; d) Valores relativos de absorvência, medida a $276 \mathrm{~nm}$; e) Variação de $\mathrm{pH} ;$ f) Valores relativos de condutividade. 


\section{2- Identificação dos metabolitos por HPLC}

As amostras recolhidas ao longo do tempo de ensaio, realizado com o ânodo de $\mathrm{Ti} / \mathrm{Pt} / \mathrm{SnO}_{2}-\mathrm{Sb}$, foram analisadas por $\mathrm{HPLC}$, estando os resultados apresentados na Figura 4. Podemos verificar que há o aparecimento de vários ácidos carboxílicos onde suas estruturas demonstrada na Figura 5, cuja concentração aumenta até às $4 \mathrm{~h}$ de ensaio, verificando-se, após esse tempo, uma estabilização da sua concentração. Este fato deve-se a diminuição da concentração de diclofenac, onde começa dar-se a degradação preferencial dos intermediários formados. A degradação destes intermediários faz-se com uma eficiência de combustão diferente, o que leva a uma alteração no decréscimo da razão $\triangle C O T / \triangle D Q O$, observado na Figura 3.

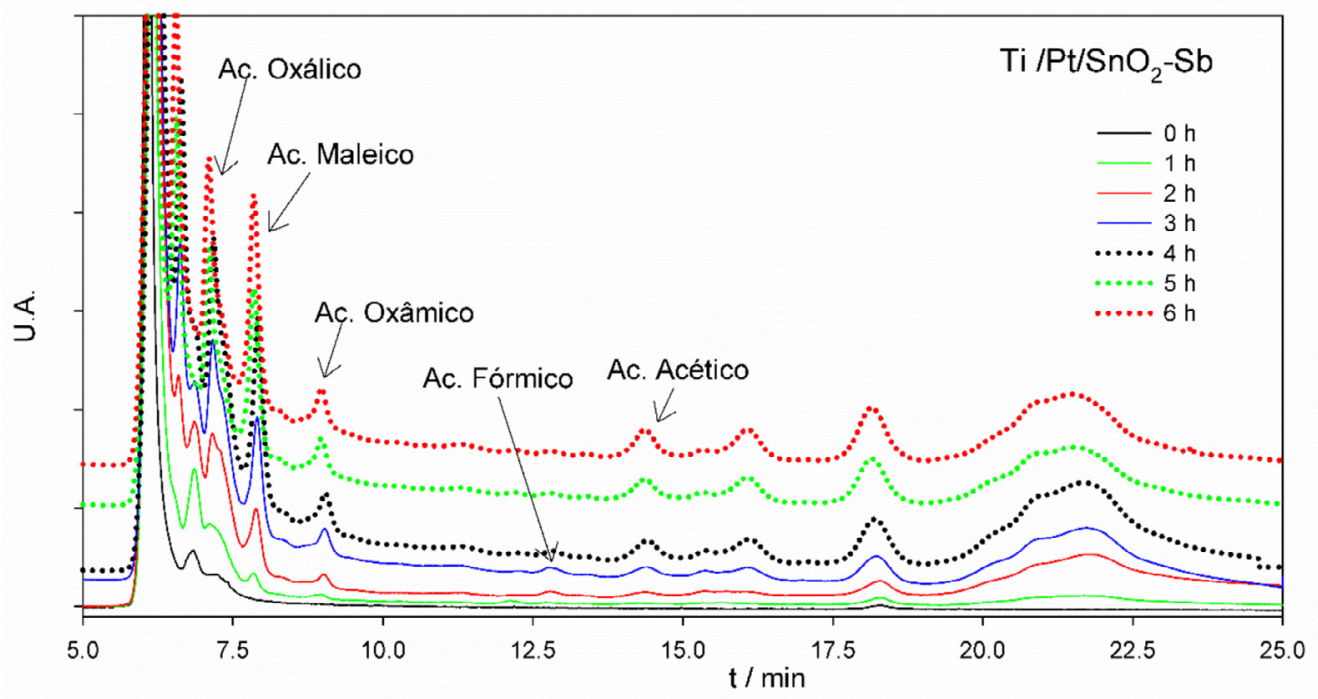

Figura 4. Resultados obtidos por HPLC para as amostras recolhidas ao longo do ensaio de degradação do diclofenac com o ânodo de $\mathrm{Ti} / \mathrm{Pt} / \mathrm{SnO}_{2}$-Sb. 


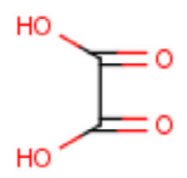

Ácido oxálico

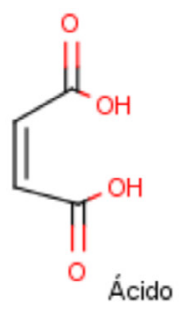

Maleico<smiles>NC(=O)C(=O)O</smiles>

Ácido Oxâmico<smiles>O=CO</smiles>

Ácido fórmico

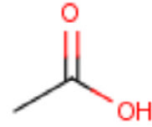

Ácido acético

Figura 5. Estruturas dos ácidos identificados pela degradação do diclofenac por HPLC

\section{5- Conclusão}

Os resultados obtidos na degradação eletroquímica do diclofenac com os dois ânodos utilizados, o de $\mathrm{Ti} / \mathrm{Pt} / \mathrm{SnO}_{2}-\mathrm{Sb}$ e o de $\mathrm{BDD}$, mostraram que a oxidação anódica é um processo eficiente para a degradação deste fármaco em qualquer um destes dois materiais de eletrodo.

Relativamente aos resultados conseguidos com o elétrodo de $\mathrm{Ti} / \mathrm{Pt} / \mathrm{SnO}_{2}-\mathrm{Sb}$, obtiveram-se reduções de DQO, de COT e de absorvência de 38, 42 e 31\%, respetivamente, ao fim de $6 \mathrm{~h}$ de ensaio. Há ainda a registar uma ligeira diminuição do $\mathrm{pH}$ ao longo do ensaio, que deve estar relacionada com a formação de ácidos carboxílicos. A condutividade também sofre uma ligeira redução ao longo do tempo, que pode estar relacionada com formação de espécies poliméricas, pois observa-se a formação de turvação nas amostras recolhidas após algum tempo.

Em relação ao eletrodo de BDD, este apresentou maior eficiência na degradação do Diclofenac, tendo-se obtido remoções na CQO, no TOC e na absorvência de 70, 77 e $86 \%$, respetivamente, ao fim de $6 \mathrm{~h}$ de ensaio, valores estes que são aproximadamente o dobro dos obtidos com o eletrodo de $\mathrm{Ti} / \mathrm{Pt} / \mathrm{SnO}_{2}-\mathrm{Sb}$. Em relação à variação do $\mathrm{pH}$ ao longo dos ensaios, observou-se, no caso do BDD, um decréscimo inicial seguido de um acréscimo, sendo o pH final superior ao inicial. Neste caso, o fator dominante deverá estar relacionado à formação excessiva de radicais hidroxila.

Em relação à variação da razão $\triangle \mathrm{COT} / \triangle \mathrm{DQO}$ ao longo do ensaio, os ensaios conduzidos com os dois materiais de eletrodo, apesar da desfasagem no tempo, apresentam andamentos muito semelhantes. Como perspetivas de trabalho futuro, destacam-se as seguintes: 
- Estudar o decaimento do Diclofenac, por HPLC, nas condições experimentais usadas neste trabalho.

- Tentar identificar os produtos que foram detectados por HPLC, mas que não foram identificados, por falta de padrões.

- Realizar ensaios de degradação do Diclofenac em condições experimentais diferentes, i.e., a diferentes densidades de corrente e diferentes concentrações do fármaco e usando como eletrólito um sal de cloro. Utilizar outros materiais de ânodo, à base de óxidos de estanho e antimônio, como o Ti/ $/ \mathrm{SnO}_{2}-\mathrm{Sb}$.

- Estender este estudo a outros compostos farmacêuticos, como hormonio. 


\section{Identification of metabolites of the anodic oxidation of diclofenac by HPLC}

Abstract: This research aims to study the efficiency of the electrochemical degradation of Diclofenac, using boron-doped diamond anodes (BDD) and $\mathrm{Ti} / \mathrm{Pt} / \mathrm{SnO} 2-\mathrm{Sb}$ anodes, and identify, by HPLC, the metabolites resulting from the anodic oxidation. Electrodegradation assays were monitored by determination of chemical oxygen demand (COD) and total organic carbon (TOC). Ultraviolet-visible absorption spectra were also performed and measurements of $\mathrm{pH}$ and conductivity were also made.

The results show that the two electrode materials are suitable as anodes for the degradation of Diclofenac, since there is a reduction in time of COD, TOC and absorbance, measured at $276 \mathrm{~nm}$. The $\mathrm{pH}$ results are consistent with the formation of carboxylic acids. The results of the conductivity measurements indicate the possibility of the formation of polymeric species in the process. The best results in terms of removal of organic matter were obtained with the BDD anode. After $6 \mathrm{~h}$ assay, removals of 70 and $38 \%$ in COD, 77 and $42 \%$ in TOC and 86 and $31 \%$ in absorbance were obtained for BDD and $\mathrm{Ti} / \mathrm{Pt} / \mathrm{SnO} 2-\mathrm{Sb}$ anodes, respectively.

The identification of the products resulting from anodic oxidation was done by HPLC and the following carboxylic acids, resulting from the degradation of Diclofenac, were identified: oxalic acid, maleic acid, oxamic acid, formic acid and acetic acid. Some of these acids subsequently undergo degradation, leading to a change in the combustion efficiency throughout the test. Thus, during the first part of the test, the ratio $\triangle \mathrm{COT} / \triangle \mathrm{DQO}$ corresponds to the Diclofenac degradation and, in the second part of the assay, that ratio corresponds to the degradation of carboxylic acids formed meanwhile.

Keywords: $\mathrm{Ti} / \mathrm{Pt} / \mathrm{SnO} 2-\mathrm{Sb} ; \mathrm{BDD}$; electrochemical oxidation

\section{Referências bibliográficas}

Anglanda, A.; Urtiaga, A.; Ortiz, I. Contributions of electrochemical oxidation to waste-water treatment: fundamentals and review of applications. Journal of Chemical Technology and Biotechnology, v. 84, p. 1747-1755, 2009. 
Batista, C.E.; Oliveira, D.S.T.R.; Ferreira, Q.D.R.; Miwa, D.; Santos, D.C.M. Degradação Eletroquímica da vinhaça usando eletrodo de diamante dopado com boro. Química Nova, v. 34, n. 9, p. 1517-1520, 2011.

Bertazzoli, R.; Pelegrini, R. Descoloração e degradação de polventes orgânicos em soluções aquosas através do processo fotoeletroquímico. Química Nova, v. 9, n. 3, p. 655-661, 2002.

Bila, M.D.; Dezotti, M. Fármacos no meio ambiente. Química Nova, v. 26, n. 4, p. 523 - 530, 2003.

Brinzila, C.I.; Pacheco, M.J.; Ciríaco, L.; Ciobanu, R.C.; Lopes, A. Electrodegradation of tetracycline on BDD anode. Chemical Enginneering Journal, v. 209, p. 54-61, 2012.

Costa, D.S.A.; Costa, S.M. Polventes farmacêuticos: a polvição silenciosa. Jornal Eletrônico: Faculdades Integradas Vianna Junior, v.3, n. 1, p. 95-107, 2011.

Eaton, A.D.; Clesceri, L.S.; Greenberg, A.E. Standard Methods for Examination of Water and Wastewater. American Public Health Association, Washington, D.C, v. 19, 1995.

Freire, R.S; Pelegrini, R.; Kubota, L.T.; Duran, N. Novas tendências para o tratamento de resíduos industriais contendo espécies organoclorados. Química Nova, v. 23, n. 4, p. $504-51$ 1, 2000.

Glaze, W.H. Drinking water treatment with ozone. Environmental Science and Technology, v. 21, p. 224-230, 1987. ISSN 0013-936X.

Kopin, D.W.; Furlong, E.T.; Meyer, M.T.; Thurman, E.M.; Zaugg, S.D.; Barber, L.B.; Buxton, H.T. Pharmaceuticals, hormones, and other organic wastewater contaminants. In: US streams, 19992000: a national reconnaissance. Environ. Sci. Tech, v. 36, n. 6, p. 1202-1211, 2002.

Lima, B.A.; Chaves, C.S.; Silva, D.M.L.; Pereira, F.P.; Richter, M.E.; Santos, D.P.T.W. Determinação de nimesulida por análises por injeção em fluxo com detecção amperométrica de múltiplos pulsos. Química Nova, v. 36, n.9, p. 1296-1302, 2013.

Martinez-Huitle, C.A.; Brillas, E. (2009). Decontamination of wastewaters containing synthetic organic dyes by electrochemical methods: a general review. Applied Catalysis, v. 87, p. 105-145, 2009. 
Pacheco, M.J.; Morão, A.; Lopes, A.; Ciríaco, L.; Gonçalves, I. Degradation of phenols using boron doped diamond electrodes: a method for quantifying the extent of combustion. Electrochimica Acta, v. 53, n. 2, p. 629-636, 2007.

Panizza, M.; Cerisola, G. Application of diamond electrodes to electrochemical processes. Electrochimica Acta, v. 51, p. 191-199, 2005.

Panizza, M.; Cerisola, G. Direct and mediated anodic oxidation of organic pollutants. Chemical Reviews, v. 109, p. 6541-6569, 2009.

Paterson, J.M.; Anderson, G.M.Trial Prescriptions to reduce drug wastage: results from Canadian Programs and a Community Demonstration Project. American Journal of Managed Care, v. 8, n. 2, p. 151-158, 2002.

Pera-Titus, M.P.; Garcia-Molina, V.; Banos, M.A.; Gimenez, J.; Esplugas, S. Degradation of chlorophenols by means of advanced oxidation processes: a general review. Applied Catalys $B, v$. 47 , p. $219-256,2004$.

Santos, D.; Pacheco, J.M.; Gomes, A.; Lopes, A.; Ciríaco, L. Preparation of Ti/Pt/SnO2-Sb2O4 electrodes for anodic oxidation of pharmaceutical drugs. J Appl Electrochem, v. 43, p. 407-416, 2013.

Santos, V.; Morão, A.; Pacheco, M.; Ciríaco, L.; Lopes, A. Eletrochemical degradation of azo dyes on BDD: Effect of chemical structure and operating conditio non the combustion efficiency. Journal of Environmental Management, v. 18, p. 193-204, 2009.

Santos, D.; Lopes, A.; Pacheco, M.J.; Gomes, A.; Ciríaco, L. The Oxygen Evolution Reaction at SnSb Oxide Anodes: Influence of the Oxides Preparation Mode. Journal of the electrochemical Society, v. 161, n. 9, p. 564-572, 2014.

Teixeira, B.A.D.P.C.; Jardim, F.D.W. Processos Oxidativos Avançados. Apresentado na Universidade Estadual de Campinas (UNICAMP), v. 3, 2004.

Zhao, X.; How, Y.; Liu, H.; Qiang, Z.; Qu, J. Electro-oxidation of diclofenac at boron doped diamond: Kinetics and mechanism. Electrochimica Acta, v. 54, p. 4172-4179, 2009.

Zanin, H.; Teófilo, F.R.; Peterlevitz, C.A.; Oliveira, U.; Paiva, D.C.I.; Ceragioli, J.H.; Reis, L.E.; Baranauskas, V. Diamond cylindrical anodes for electrochemical treatment of persistente compounds in aqueous solution. J Appl Electrochem, v. 43, p. 323-330, 2013. 